\title{
Solution for Injection in Needle-Free Injector
}

National Cancer Institute

\section{Source}

National Cancer Institute. Solution for Injection in Needle-Free Injector. NCI Thesaurus.

Code C149916.

Medicinal product consisting of a solution for injection presented in a needle-free injector. 